\title{
Weak interplate coupling beneath the subduction zone off Fukushima, NE Japan, inferred from GPS/acoustic seafloor geodetic observation
}

\author{
Yoshihiro Matsumoto $^{1 *}$, Tadashi Ishikawa ${ }^{1}$, Masayuki Fujita $^{1}$, Mariko Sato $^{1}$, Hiroaki Saito ${ }^{1}$, \\ Masashi Mochizuki ${ }^{2}$, Tetsuichiro Yabuki ${ }^{1}$, and Akira Asada ${ }^{2}$ \\ ${ }^{1}$ Hydrographic and Oceanographic Department, Japan Coast Guard, 5-3-1 Tsukiji, Chuo-ku, Tokyo 104-0045, Japan \\ ${ }^{2}$ Institute of Industrial Science, the University of Tokyo, 4-6-1 Komaba, Meguro, Tokyo 153-8505, Japan
}

(Received April 30, 2008; Revised June 5, 2008; Accepted June 9, 2008; Online published June 18, 2008)

\begin{abstract}
We have been carrying out GPS/acoustic seafloor geodetic observations at several reference points situated along the Japan Trench, a major plate boundary of subduction. A time series of horizontal coordinates of one of the seafloor reference points, located off Fukushima, obtained from seven campaign observations for the period 2002-2008, exhibits a linear trend with a scattering root mean square of about $3 \mathrm{~cm}$. A linear fit to the time series gives an intraplate crustal movement velocity of $3.1 \mathrm{~cm}$ per year in a westerly direction, which is significantly smaller than that at the other seafloor reference point $120 \mathrm{~km}$ away along the trench axis. This result implies weak interplate coupling in this region.
\end{abstract}

Key words: GPS/acoustic, seafloor geodetic observation, back-slip, Off Fukushima, intraplate deformation.

\section{Introduction}

The northeastern part of Japan, where the Pacific Plate is subducting beneath the continental plate at a rate of 9-10 cm/year (DeMets et al., 1994), is a seismically active region, especially in the area off-shore Miyagi Prefecture, where large interplate earthquakes with magnitudes of about 7.5 occur repeatedly at an average interval of about 37 years (the Headquarters for Earthquake Research Promotion, 2000). Various research projects have focused on determining the characteristics of future hazardous earthquakes as well as elucidating the active tectonics of this region. Among these, distribution of the asperities has been estimated based on regional seismic data from interplate earthquakes (e.g. Yamanaka and Kikuchi, 2004). The backslip estimation based on crustal surface deformation data is another major approach that has been used to elucidate the distribution of asperities in this region (e.g. Suwa et al., 2006). These studies as a whole suggest the existence of asperities and strong interplate coupling off Miyagi.

In contrast, the degree of seismic coupling off Fukushima Prefecture, bordered on the north by Miyagi Prefecture, is not conclusive. Based on the fact that the only major event known to have taken place within the last 400 years is a group of several earthquakes with magnitudes of approximately 7.5 that occurred in 1938 , the recurrence interval of large earthquakes in this region is assumed to be 400 years or longer (the Headquarters for Earthquake Research Promotion, 2002). Microseismicity in this region, however,

*Now at Embassy of Japan in Malaysia, No.11 Persiaran Stonor, Off Jalan Tun Razak, 50450 Kuala Lumpur, Malaysia.

Copy right(c) The Society of Geomagnetism and Earth, Planetary and Space Sciences (SGEPSS); The Seismological Society of Japan; The Volcanological Society of Japan; The Geodetic Society of Japan; The Japanese Society for Planetary Sciences; TERRAPUB is rather active, and in some areas, small repeating earthquakes occur, implying quasi-static slip instead of strong coupling (Uchida et al., 2006).

The GPS/acoustic combination technique for precise seafloor geodetic observation has been successfully used to book steady progress in filling in the gaps in information on crustal deformation in the sea area. This technique has its origins in early work carried out by scientists at the Scripps Institution of Oceanography (Spiess, 1985). Our team at the Japan Coast Guard (JCG) and the Institute of Industrial Science, the University of Tokyo, has been developing this technique using a survey vessel and making repeated campaign observations along the major trenches (Asada and Yabuki, 2001; Mochizuki et al., 2003, 2005; Fujita et al., 2006a). Fujita et al. (2006a) demonstrated that the repeatability of the position determination reaches an accuracy of a couple of centimeters under good conditions and proved the capability of detecting secular crustal movement at a seafloor reference point located off Miyagi Prefecture.

In the region off Fukushima Prefecture, we installed a seafloor reference point, denoted FUKU, on the landward side of the Japan Trench in 2001 with the aim of detecting and monitoring the secular intraplate crustal movement caused by the subduction of the Pacific Plate near the plate boundary. A research group of Tohoku University also installed a number of seafloor transponders in this region, and Mizukami et al. (2007) recently reported that they have been able to detect intraplate deformation with a similar observation system as that used by our group, but with a towed buoy.

Here, we present and discuss the crustal movement that we have detected at our seafloor reference point FUKU based on our observations from 2002 to 2008 . 


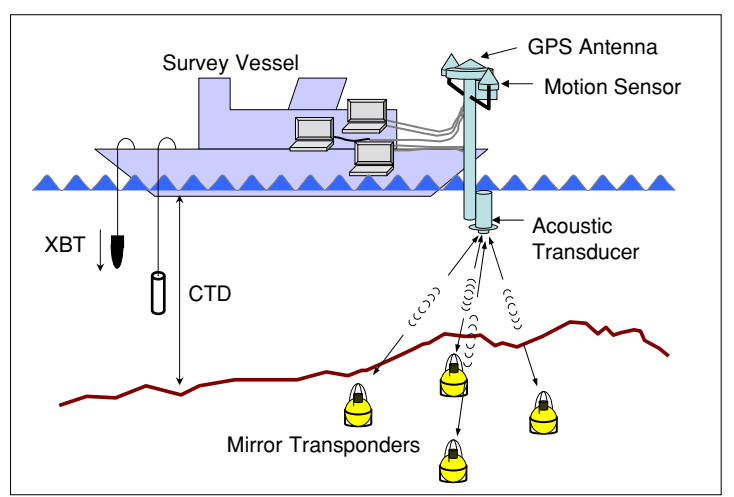

Fig. 1. Schematic picture of the GPS/acoustic seafloor geodetic observation system.

\section{Seafloor Geodetic Observation and Analysis}

A schematic picture of the seafloor geodetic observation system that we have developed is shown in Fig. 1. This system consists of a seafloor unit with four or three acoustic mirror-type transponders and an on-board unit with a GPS antenna and an undersea acoustic transducer installed on the rigid observation pole ( $8 \mathrm{~m}$ in length) to which a motion sensor is also attached.

The system measures ranges from the on-board transducer to the seafloor acoustic transponders through roundtrip acoustic travel times, while simultaneously determining coordinates of the on-board transducer by transferring from those of the GPS antenna using the attitude of the observation pole measured with the motion sensor. Positions of the GPS antenna are determined using a kinematic GPS software called 'IT' (for Interferometric Translocation), which was developed for the precise determination of the trajectory of a rover over very long baselines (Colombo and Evans, 1998; Colombo et al., 2000, 2001). The acoustic wave velocity profile in the seawater, which is necessary for transforming travel times into ranges, is obtained from CTD, XCTD and XBT measurements.

Positions of the transponders are finally calculated by a linear inversion method based on least squares formulation combining round-trip travel times and kinematic GPS positions. The positions of grouped transponders are finally averaged to be a virtual position of the reference point.

For more details on the methodology, the reader is referred to Fujita et al. (2006a)

\section{Location of the Seafloor Reference Point and Observation Result}

The seafloor reference point FUKU is situated about $150 \mathrm{~km}$ landward from the axis of the Japan Trench (Fig. 2). A set of four acoustic transponders has been installed on the seafloor, at a depth of about $1200 \mathrm{~m}$. The transponders were placed to form a square whose four corners are directed to the north, south, east and west, respectively. This reference point has been working since 2001. We have carried out seven campaign observations at FUKU for the period from July 2002 to March 2008.

In principle, our method of analysis can determine the three components of the position of a seafloor station,

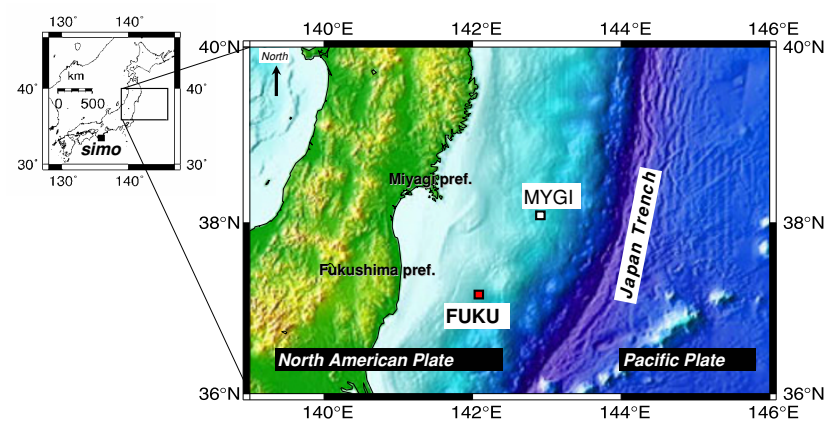

Fig. 2. Locations of the seafloor reference points used in this study shown on the topographic map around northeastern Japan. The red filled square and the open square represents FUKU and MYGI, respectively. Also shown is the position reference, the Shimosato site (a solid square labeled as 'simo').

i.e. two horizontal components and height. Nevertheless, Ishikawa and Fujita (2005) proposed that, in order to obtain a horizontal time series as accurately as possible, it is usually most effective to fix the heights of all the epochs to some reasonable value. In the case of FUKU, it can be reasonably assumed that no significant vertical movement is expected, as this region has undergone no major earthquake during the campaign period used in this study. We used a height value formerly obtained from the epoch in January 2007 for the constrained height through analyses for all the epochs.

Data numbers for each campaign epoch used in this paper are listed in Table 1. The root mean square (rms) of the round-trip travel time residuals for each campaign analysis, also shown in Table 1, are 50-90 $\mu$ s, which corresponds to 4-7 cm in the one-way range.

Figure 3 shows the time series of estimated horizontal coordinates. Each solid circle represents the average of the coordinates of four acoustic transponders on the seafloor, relative to the reference campaign epoch of March 2008. Error bars demonstrate changes in the configuration of the four transponders compared to those of the reference solution (see Fujita et al. (2006a) for the details). The position reference is the Shimosato site in Wakayama Prefecture, central Japan, which is one of the ITRF stations also equipped for satellite laser ranging (SLR) observations (Altamimi et al., 2002). It must be noted that Shimosato underwent coseismic displacement, amounting to $1.5 \mathrm{~cm}$ to the south and $0.9 \mathrm{~cm}$ to the west, due to the occurrence of earthquakes off southeastern Kii Peninsula ( $M=6.9, M=7.4$ ) on September 2004, as revealed by the continuous GPS measurement (Japan Coast Guard, 2005). The plot of the last five epochs in Fig. 3 represent the values after the correction with this displacement. It should also be noted that Shimosato is located on the eastern edge of the Eurasian Plate (EU), which is known to undergo the intraplate deformation at a rate of about $3 \mathrm{~cm} /$ year west-northwest due to pressure from subduction of the Philippine Sea Plate.

The time series shown in Fig. 3 exhibits a linear trend in time, with a repeatability of several centimeters. A linear fit to the time series gives a rate of $0.1 \pm 0.3 \mathrm{~cm} /$ year westward and $0.9 \pm 0.6 \mathrm{~cm} /$ year southward. The rms around the fitted 
Table 1. List of numbers of data for each campaign observation at the seafloor reference point FUKU used in this study. RMS of round-trip travel time residuals for each campaign analysis is also listed.

\begin{tabular}{cccccccc}
\hline Epoch & Jul & Jun & Jul & Jul & Jan & Jul & Mar \\
& 2002 & 2003 & 2005 & 2006 & 2007 & 2007 & 2008 \\
\hline Days & 2 & 4 & 3 & 5 & 8 & 2 & 1 \\
\hline Shots & 2316 & 4857 & 3401 & 6117 & 8588 & 5826 & 3062 \\
\hline $\begin{array}{l}\text { Residuals } \\
\text { RMS (ms) }\end{array}$ & 0.084 & 0.081 & 0.085 & 0.070 & 0.068 & 0.053 & 0.057 \\
\hline
\end{tabular}
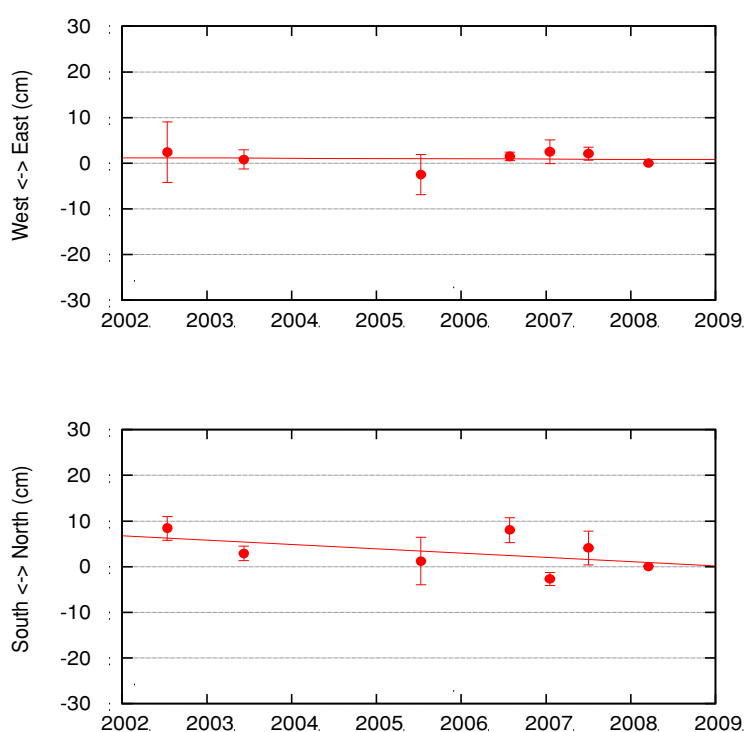

Fig. 3. Time series in the horizontal coordinates obtained at the seafloor reference station FUKU from seven campaign observations obtained during the period July 2002 to March, 2008. The top and bottom panels correspond to the east-west and north-south components, respectively. The position reference is the Shimosato site, in central Japan.

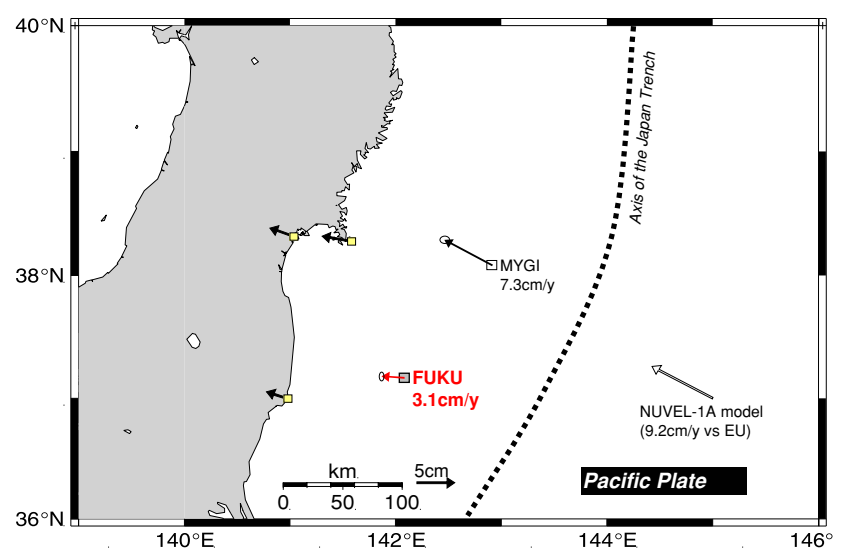

Fig. 4. Crustal movement velocity vector with one-sigma estimation error ellipse at FUKU relative to the Eurasian Plate (EU) evaluated from the time series shown in Fig. 3 after correcting for the intraplate velocity at Shimosato (3.2 cm/year, $291^{\circ}$; Sengoku, 1998). The crustal movement velocity vectors at MYGI (Fujita et al., 2006b) and three of Japan Coast Guard's on-land GPS stations are also shown. The velocity of the Pacific Plate relative to the EU around this region calculated from the plate motion model, NUVEL-1A (DeMets et al., 1994), is also shown (open arrow). line are $1.6 \mathrm{~cm}$ in the east-west component and $3.3 \mathrm{~cm}$ in the north-south component. When we add the intraplate velocity of Shimosato $\left(3.2 \mathrm{~cm} /\right.$ year, $291^{\circ}$; Sengoku, 1998) to the above rate, we obtain $3.1 \mathrm{~cm} /$ year, with an azimuth of $275^{\circ}$, relative to the stable part of the EU, which is denoted with an arrow in Fig. 4.

\section{Discussion}

Secular seafloor movements at some other sites near FUKU have already been reported. Fujita et al. (2006b) showed that the displacement velocity vector at a reference point labeled as MYGI on the EU, $120 \mathrm{~km}$ northeast of FUKU, was $7.3 \mathrm{~cm} /$ year, with an azimuth of $300^{\circ}$ versus that from ten seafloor campaign observations on the EU for the period 2002-2005. This is an updated result of that reported by Fujita et al. (2006a), based on reanalysis with improved software adding a new data set. Considering that the velocity of the Pacific Plate relative to the EU along the Japan Trench is 9-10 cm/year, according to contemporary plate motion models (e.g. NUVEL-1A; DeMets et al., 1994), the interplate coupling at MYGI is very strong, even if we would allow for errors in the velocities of a few centimeters per year. These results are consistent with those of previous studies (e.g. Suwa et al., 2006).

In contrast, the estimated value at FUKU, $3.1 \mathrm{~cm} / \mathrm{year}$, is significantly smaller than at that at MYGI. On the Pacific coast of the Fukushima region, the amount of velocity relative to the EU is about 3-4 cm/year; this becomes progressively smaller inland, down to approximately $2.5 \mathrm{~cm} /$ year (Miura et al., 2004). Our resultant displacement velocity is at the same level of the above movement on land, and its direction is also consistent.

It should be noted that Mizukami et al. (2007) also present a displacement velocity vector at their array of transponders (labeled as GFK) on the EU, $80 \mathrm{~km}$ northeast from FUKU, based on their campaign observation from $\mathrm{Au}-$ gust 2005 to July 2006. Although the magnitude of their displacement velocity seems to exceed a possible maximum, its direction is consistent. As a result, they suggest that the interplate coupling around their site is as strong as that at MYGI. The discrepancy between the velocities at FUKU and GFK is possibly associated with spatial variation in interplate coupling, as GFK is closer to the trench axis.

Based on the estimation of back-slip by Suwa et al. (2006) using observation data of an on-land GPS network, the magnitude of back-slip in this area peaks at $10 \mathrm{~cm} / \mathrm{year}$ near MYGI, and gradually diminishes around FUKU. According to a study by Uchida et al. (2006), which investi- 


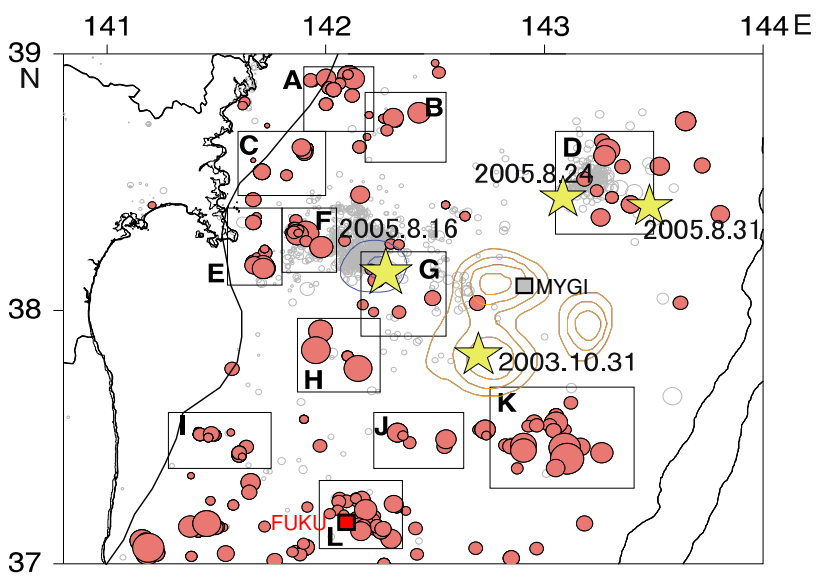

Fig. 5. Distribution of small repeating earthquakes is shown with orange circles after Uchida et al. (2006). Location of the seafloor reference points FUKU and MYGI are added by the author (red-filled square and a gray-filled square, respectively). Uchida et al. (2006) estimated the averaged cumulative slip to be $1.5-2 \mathrm{~cm} /$ year within the sampling window ' $\mathrm{L}$ ', where FUKU is located.

gated interplate creep in this area using a 21-year history of small repeating earthquakes, FUKU is located in one of the active regions of small repeating earthquakes, while MYGI is not (Fig. 5). These researchers suggest the existence of creep by small repeating earthquakes and estimate the averaged cumulative slip around FUKU to be $1.5-2 \mathrm{~cm} /$ year. The significantly small amount of our displacement velocity at FUKU is roughly consistent with the lack of back-slip around FUKU caused by the creep, which indicates weak interplate coupling in the region. For a more quantitative discussion of coupling strength, we need to improve the accuracy of our velocity determination by accumulating further good data from future surveys.

Acknowledgments. We thank Dr. Oscar L. Colombo of the NASA Goddard Space Flight Center for providing us with the kinematic GPS software 'IT'. We thank the Geographical Survey Institute of Japan for providing us with the GEONET GPS data at 1 -s sampling for our kinematic GPS analyses. We are indebted to Dr. Zengo Yoshida of the Institute of Industrial Science, the University of Tokyo, for his sincere support to this project. Advice from Dr. Azusa Nishizawa was instructive. A great many staff members of the Hydrographic and Oceanographic Department of Japan Coast Guard, including the crew of S/Vs Meiyo and Kaiyo, have been very supportive in making observations and data analyses. The comments of Dr. C. D. Chadwell and an anonymous referee have improved the manuscript substantially. Some figures were produced with the GMT software (Wessel and Smith, 1991).

\section{References}

Altamimi, Z., P. Sillard, and C. Boucher, ITRF2000: A new release of the International Terrestrial Reference Frame for earth science applications, J. Geophys. Res., 107(B10), 2214, doi:10.1029/2001JB000561, 2002.

Asada, A. and T. Yabuki, Centimeter-level positioning on the seafloor, Proc. Jpn. Acad. Ser. B, 77, 7-12, 2001.

Colombo, O. L. and A. G. Evans, Precise, decimeter-level differential GPS over great distances at sea and on land, Proc. ION GPS-98, Nashville, Tennessee, 1998.
Colombo, O. L., A. G. Evans, M. I. Vigo-Aguiar, J. M. Ferrandiz, and J. J. Benjamin, Long-baseline (>1000 km), sub-decimeter kinematic positioning of buoys at sea, with potential application to deep sea studies, Proc. ION GPS2000, Salt Lake City, Utah, U.S.A., 2000.

Colombo, O. L., A. G. Evans, M. Ando, K. Tadokoro, K. Sato, and T. Yamada, Speeding up the estimation of floated ambiguities for subdecimeter kinematic positioning at sea, Proc. ION GPS-2001, Salt Lake City, Utah, U.S.A., 2001.

DeMets, C., R. G. Gordon, D. F. Argus, and S. Stein, Effect of recent revisions to the geomagnetic reversal time scale on estimates of current plate motions, Geophys. Res. Lett., 21, 2191-2194, 1994.

Fujita, M., T. Ishikawa, M. Mochizuki, M. Sato, S. Toyama, M. Katayama, K. Kawai, Y. Matsumoto, T. Yabuki, A. Asada, and O. L. Colombo, GPS/Acoustic seafloor geodetic observation: method of data analysis and its application, Earth Planets Space, 58, 265-275, 2006a.

Fujita, M., Y. Matsumoto, T. Ishikawa, M. Mochizuki, M. Sato, S. Toyama, K. Kawai, T. Yabuki, A. Asada, and O. L. Colombo, Combined GPS/Acoustic seafloor geodetic observation system for monitoring offshore active seismic regions near Japan, Proc. ION GNSS-2006, Fort Worth, Texas, U.S.A., 2006 b.

Ishikawa, T. and M. Fujita, Inverse method and precision improvement for seafloor positioning, Rep. Hydrogr. Oceanogr. Res., 41, 27-34, 2005 (in Japanese with English abstract).

Japan Coast Guard, GPS observation for monitoring crustal movements in Zeni Su in 2004, DATA Report of Hydrogr. Oceanogr. Observ. Ser. Satellite Geod., 18, http://www1.kaiho.mlit.go.jp/jhd-E.html, Tokyo, Japan, 2005 (in Japanese).

Miura, S., T. Sato, A. Hasegawa, Y. Suwa, K. Tachibana, and S. Yui, Strain concentration zone along the volcanic front derived by GPS observations in NE Japan arc, Earth Planets Space, 56, 1347-1355, 2004.

Mizukami, T., H. Fujimoto, Y. Osada, M. Kido, and S. Miura, Repeated seafloor geodetic measurements off Fukushima Prefecture using the GPS/Acoustic positioning system, Abstr. JPGU Meet. 2007, J169-015, 2007.

Mochizuki, M., M. Sato, M. Katayama, T. Yabuki, Z. Yoshida, and A. Asada, Construction of seafloor geodetic observation network around Japan, Recent advances in marine science and technology, 2002, 591$600,2003$.

Mochizuki, M., M. Fujita, M. Sato, Z. Yoshida, M. Katayama, T. Yabuki, and A. Asada, Repeated trials of seafloor geodetic observation around Japan, Recent advances in marine science and technology, 2004, 11-18, 2005 .

Sengoku, A., A plate motion study using Ajisai SLR data, Earth Planets Space, 50, 611-627, 1998.

Spiess, F. N., Suboceanic geodetic measurements, IEEE Trans. Geosci. Remote Sens., GE-23, 4, 502-510, 1985.

Suwa, Y., S. Miura, A. Hasegawa, T. Sato, and K. Tachibana, Interplate coupling beneath NE Japan inferred from three dimensional displacement field, J. Geophys. Res., 111, doi:101029/2004JB003203, 2006.

The Headquarters for Earthquake Research Promotion, Long-term evaluatioin of the Off-Miyagi earthquakes, http://www.jishin.go.jp/ main/index.html, Tokyo, Japan, 2000 (in Japanese).

The Headquarters for Earthquake Research Promotion, Long-term evaluation of seismic activities off-Sanriku to off-Bousou, http://www. jishin.go.jp/main/index.html, Tokyo, Japan, 2002 (in Japanese).

Uchida, N., T. Matsuzawa, S. Hirahara, and A. Hasegawa, Small repeating earthquakes and interplate creep around the 2005 Miyagi-oki earthquake (M=7.2), Earth Planets Space, 58, 1577-1580, 2006.

Wessel, P. and W. H. F. Smith, Free software helps map and display data, EOS Trans. AGU, 72, 441, 445-446, 1991.

Yamanaka, Y. and M. Kikuchi, Asperity map along the subduction zone in northeastern Japan inferred from regional seismic data, J. Geophys. Res., 109, B07307, doi:10.1029/2003JB002683, 2004.

Y. Matsumoto (e-mail: yoshihiro@matsumo.to), T. Ishikawa, M. Fujita, M. Sato, H. Saito, M. Mochizuki, T. Yabuki, and A. Asada 